\title{
Research on Service Network Governance Structure
}

\author{
Guihong $\mathrm{Xu}^{1, \mathrm{a}}$ Jingfeng $\mathrm{Zhao}^{2, \mathrm{~b}}$ and Haizhen $\mathrm{Wu}^{3, \mathrm{c}}$ \\ ${ }^{1}$ Research Center of Western China's Economic Development, Northwest University, shaanxi, xi \\ 'an,China, \\ ${ }^{2}$ Research Center of Western China's Economic Development, Northwest University, shaanxi, xi \\ 'an,China \\ ${ }^{3}$ School of Management, Xi'an University of Architecture and Technology, xi'an, China \\ axuguihong@aliyun.com, b171545892@qq.com,,1084674974@qq.com
}

\section{Keywords: Service industry; Stakeholders; Network governance}

\begin{abstract}
The article analyzed the attitude and role of stakeholders in the service industry, straighten out the logic relationship, construct both bottom-up and top-down sandwich type vertical structure, but also horizontally through the multi-agent coordination management to realize the subject interests and industrial balanced network governance structure of service industry in the end, in view of the governance structure and mechanism of service industry, based on the governance oriented service industry development countermeasure and the suggestion.
\end{abstract}

\section{Introduction}

Environment worsening is one of the important challenges facing our country, this country is put forward to develop mainly in services of the third industry, the service industry especially in technology research and development and application, financial, contract energy management, education, training and other services as the main capacity, involving agricultural, industrial, commercial, construction, municipal and public institutions, residents and other services. Management of existing services or governance mode mainly contract management mode, however, the complexity of service industry, diversity characteristics determine the contract management mode can't complete coverage of the aspects of service industry, this leads to the problem of low efficiency in service management. As the main driving force for economic development in the future, the service industry needs to establish corresponding governance structure, improve management efficiency, and clarify the relationship between responsibility, power and interest in service industry. Network management is a new type of management mode, has been scholars proved that can improve the effectiveness of the management network, this paper tries to build a new model of network governance for services, in order to improve the service efficiency of governance.

\section{Literature Review}

Theory of network governance. Early corporate governance theory was mainly based on the enterprise theory of coase $^{[1]}$ : the enterprise was replaced by the non-market mode, the bureaucratic organization. Between enterprises and enterprises not only have a market price mechanism, contracts between enterprises also play a utility, so save a middle organization between corporation and market, Williamson to triple dimensions based on the above theory to prove. This form of organization is not independent, but has some characteristics of both enterprises and markets. Powell (1987) defined this new structure as a hybrid form ${ }^{[2]}$. Bourgeois and Eisenhardt (1988) pointed out that the organization was changing its structure to adapt to this changing trend ${ }^{[3]}$. Pfeffer and Baron (1988) found that there was a clear interest link between structural change and organization $^{[4-5]}$. This results in an obvious different form of governance of the traditional division and the market - the formation and formation of the form of network governance. 
Meyer, Tsui and Hinings (1993) suggested that under the condition of the environment tend to correlate multiple dimensions, network governance should be put in the position of the more important, because it comes from a myriad of theory of choice as the only one in the new organization form and exist typical ${ }^{[6]}$. Williamson to realize the contemporary industrial environment create new importance, advice, interdisciplinary research shall be conducted, including management research, beyond the category of economics and law and the development of a set of enterprise development can adapt to the 21 st century a new governance paradigm. As a new form of governance, network governance can enable enterprises to respond quickly to changes in the environment.

Stakeholder theory was originally for corporate governance, namely the target cannot be limited to maximize shareholder interests, and should be a company to create wealth maximization, to achieve this goal, the company must pay attention to the interests of all stakeholders, including employees, creditors, suppliers, customers, community and business interests ${ }^{[7]}$. This theory provides a theoretical foundation for research on industrial network governance.

Network governance structure. Industry network governance is not to build a new organization, but to introduce existing in the research field of the other management main body, and in the case of multiple subject to establish contact with the reticular interaction ${ }^{[8]}$. Therefore, the construction of industrial network governance structure has three characteristics: first, it includes not only the government, but also enterprises and social organizations outside the government. Second, it is to change the traditional unidirectional organizational communication in relation to establish the organizational contact information in all directions. Three is on the way to its emphasis on cooperation between the organization instead of the traditional command or competition, including the horizontal cooperation and vertical cooperation between the government, as well as the cooperation of government and enterprises and social organizations; Four is that the organizational connection of the form network is not rigid but flexible, it is the flexible industry organization that changes according to the task (industry project) ${ }^{[9]}$.

\section{Construction of Service Network Governance Structure}

Governance refers to the service industry in a certain governance mode, structure, service industry stakeholders has relationships between stakeholders and divided into the floorboard of the value stream flow, information communication. On the surface, it is similar to the government departments, services autonomy organization, an organizational structure composed of people, among them, the autonomous institutions including service industry associations and service mediation of non-governmental organizations, service enterprises and enterprise groups.

Attitude and role of stakeholders in the service industry. Through research and laws and regulations, literature research, affect or be affected by the development of service industry service industry development of individuals and groups, including project investors, developers and service providers, governments, ngos, public media, industry associations, the third party testing evaluation agencies, customers, researchers and academics, people (Fig 1). Because different groups represent different interests, they differ in their ability to accept risks and their expectations of profit. Therefore, they have different attitudes towards the development of the service industry.

As a service industry, the developers and suppliers of services tend to be merged into four categories: first, the government established or affiliated with the public utility company; The second type is a demonstration service enterprise affiliated with high carbon and high energy consumption enterprises; The third category is the subsidiary energy saving equipment manufacturer's service enterprise; The fourth category is a service enterprise developed by auditing and engineering consulting firms. There are two main types of financial investors in the service sector: commercial Banks and carbon funds. Services the government governance refers to the central government and local government two aspects: the central government is a country's macro policy makers, according to national conditions, formulate the corresponding industrial policies and supporting measures conducive to the development of service industry is one of their responsibility; The focus of local governments is to conscientiously understand and penetrate the spirit of the 
policies of the central government, formulate specific action plans, and promote the implementation of the policies of the service sector.

Third party inspection and evaluation institutions refer to the third-party energy saving service organizations which are independent of government organs and enterprises and institutions. Industry association is between the government and the service developers, suppliers, customers and service developers, suppliers, and for its service, consultation, communication, supervision, justice, self-discipline and coordination of social intermediary organizations. Customers include enterprises, institutions, government agencies and social families with service requirements. Public media is also called the public broadcasting service, public media or public broadcaster, is financed by the government budget and public funds are set up, the operation of the electronic media, nonprofit, researchers and academics by collecting a large number of data and field investigation, from two aspects of theory and practice for the development of service industry is put forward good advice.

To sum up, the different stakeholders in the development of service industry demand is different, therefore, from the Angle of the deep integration of their power to promote the services sector has great practical significance.

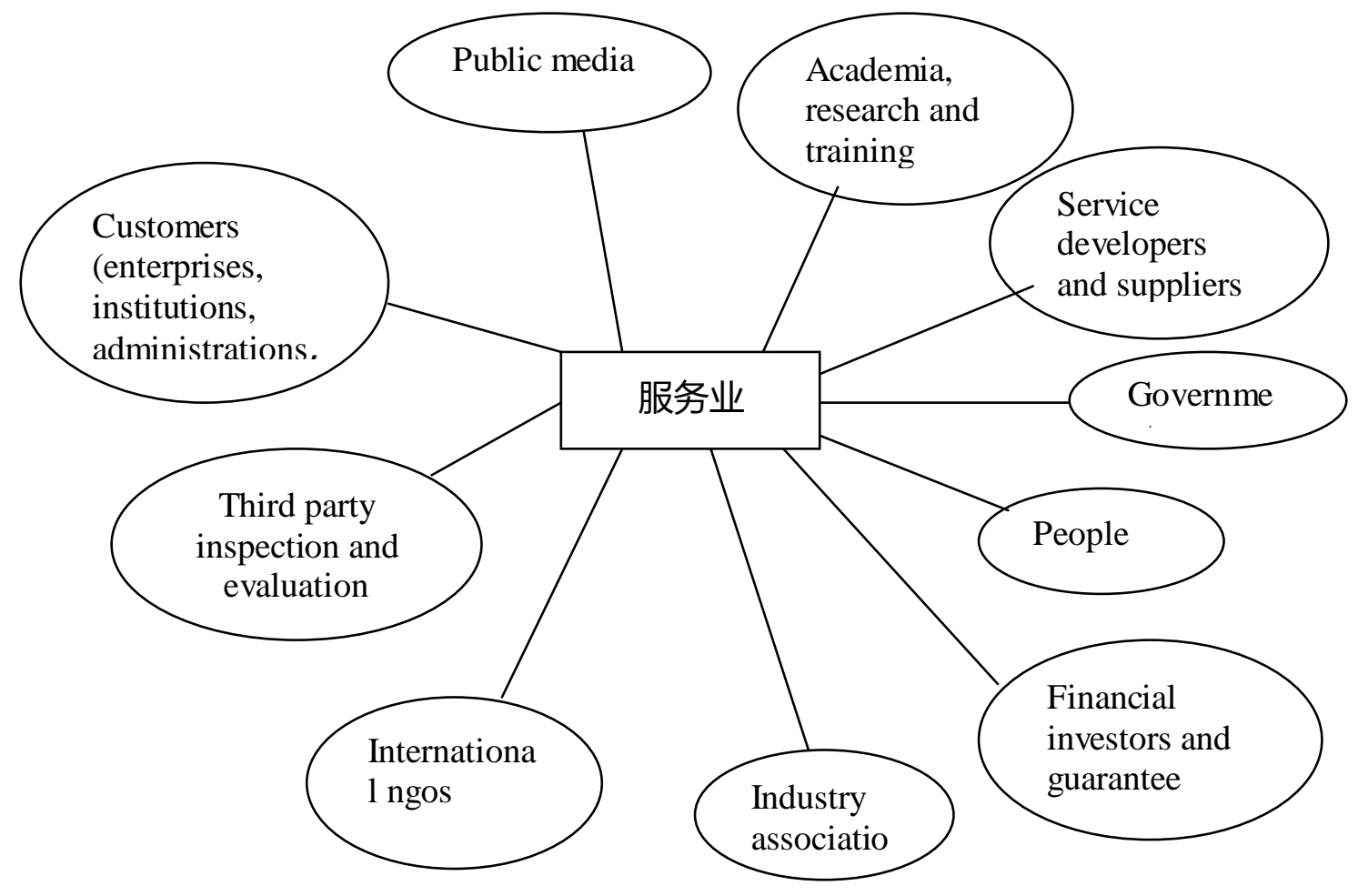

Figure 1. Stakeholders in the service industry

The governance structure based on the stakeholders. Through the analysis of the service attitude and the role of stakeholders, this paper combed the logical relationship between various stakeholders in the service sector, service industry, network governance is a kind of both bottom-up and top-down sandwich type vertical structure, and including horizontally through the multi-agent collaborative governance to achieve the interests and the interests of the whole industry equilibrium governance structure (Fig 2). In this kind of structure in different levels, different organizations, different departments need to clear their responsibility in the mission to provide organization between the information and communication, so as to solve the service industry management mode can't solve the problem.

Among them, each body that constitutes the service industry organization is a node of network organization. The links between nodes and network organizations are connected through the value chain. The reason for the formation of network organization is that the node can obtain certain 
benefits through participating in the operation of the organization, so that its own value can be realized. And the network organization has certain function, can make the node obtain the value of expectation. In a certain period, the structure (node), value and function are relatively stable. When the structure (node), value and function are changed in any of the three, it will break the original balance, promote the development of service network organization, and promote the innovation of network organization. Especially due to the change of external environment, such as the diversification and individuation of demand, the globalization of competition, etc., will lead to changes in the function of the service network, so that the value of network organization also have corresponding change, the corresponding network structure of the organization.

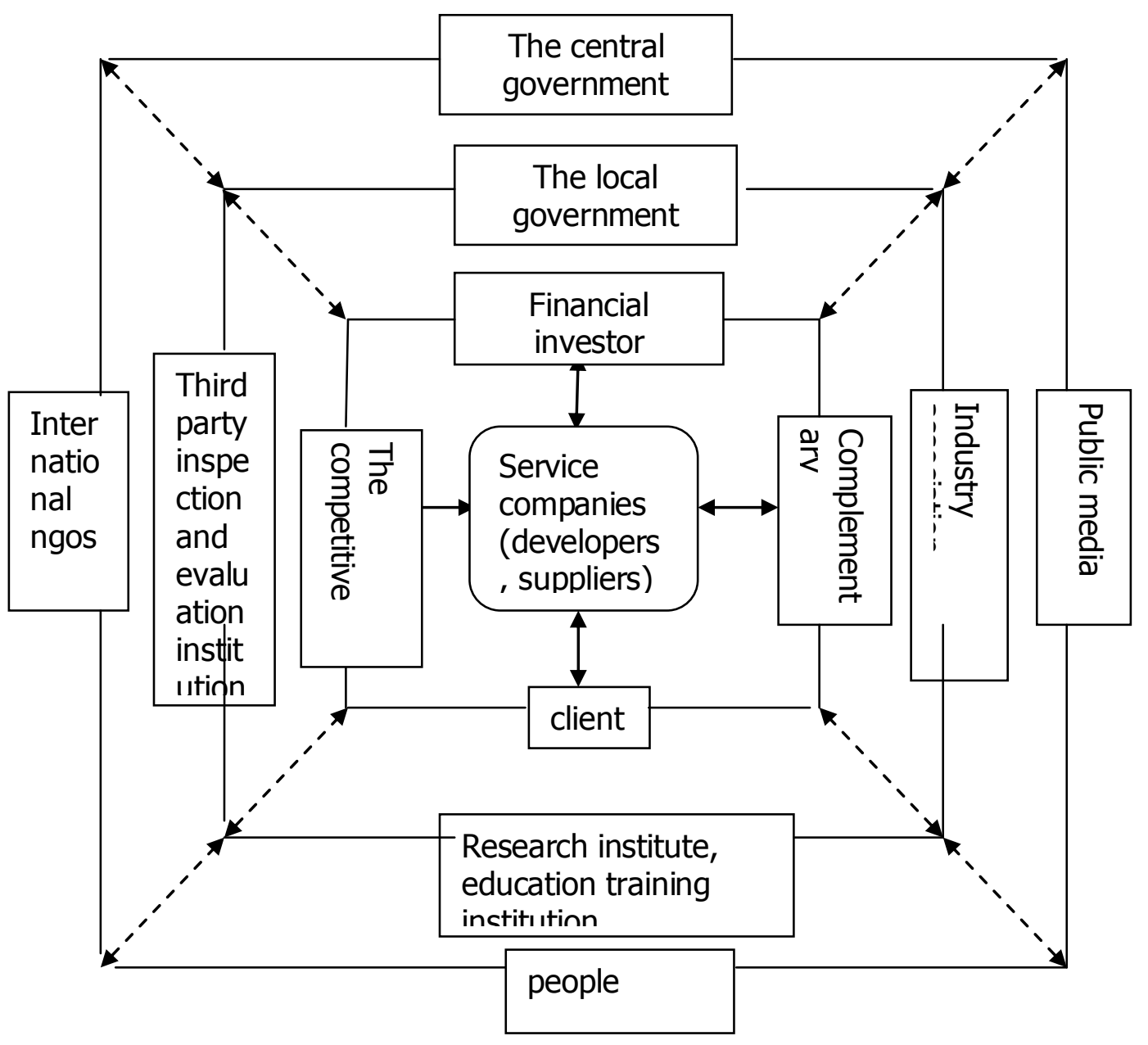

Figure 2. Model of service industry network governance structure

In Fig 2, the dotted line of the auxiliary network layer represents the boundary of the service industry and the service industry is an open system. In the strict sense, the network structure of the service industry includes only the first and second layer, which is a composite network composed of core network and auxiliary network. The two layers of network are not independent, but are closely linked based on industry contacts, knowledge sharing and social regulation and public services. The core network layer is the kernel of the service industry network structure, and the auxiliary network layer provides support for the core network layer. However, due to the industry is an open system, service industry internal stakeholders inevitably subject to communication and interaction with external environment, the service industry is one of the global industrial chain link, strengthen the cooperation and exchanges with the external network. The third layer is the external network layer, the external environment of the service industry network. Network and service industry, compared to the interaction between internal stakeholders subject service of industrial organization and the 
external network between the transmission of knowledge, information, resources, to maintain the healthy development of service industry organization network is also very important.

\section{Suggestions on the development of service-oriented services}

Establishment of a multi-party cooperative governance service development model. At present, the service demand (client) understanding of services based on the contract energy management mechanism is mainly concentrated in service projects, but for the details of the service process, the effect is not in-depth understanding. Therefore, the whole society need to be involved in the construction of service, the government should set up the service industry comprehensive coordination mechanism, such as service project guidance committee office, built around services management, coordination and service, guidance, outreach services and so on a series of public policy. In addition, by the public service advertising services related knowledge and information, establish a window and service platform for direct talks multi-stakeholder, communication, timely feedback to implement the service effect of the project, continuously improve the quality of service of service enterprises, to promote its innovation and sustainable development for service.

Use the governance mechanism to enhance the vitality of the service industry . Service enterprises in service industry vitality from the industry's capacity for independent innovation, the enterprise improve the independent innovation ability is the key to using a variety of mechanisms to improve access to resources ability and innovation consciousness. To this end, enterprises should strengthen organizational management, improve the rules and regulations, attract talents and funds, and pay attention to technology research and development. The external relations network should be established to strengthen cooperation with scientific research institutions and government departments. At the same time, introduce behavioral governance mechanism, control governance mechanism, participate in governance mechanism, technical governance mechanism, incentive governance mechanism, and balance the interests of stakeholders in the service industry. The central government, international organizations should be combined with a broad range of applicability of the service industry policy, the specification, such as green Banks, energy contract legislation, guiding the development of global service market.

\section{Acknowledgement}

Social Science Foundation of research base project of Ministry of Education,China. (15JJD790025)

\section{References}

[1] Coase R H. The Nature of the Firm[J]. Economica, 1937, 4(16):386-405.

[2] Newey W K, Powell J L. Asymmetric Least Squares Estimation and Testing[J]. Econometrica, 1987, 55(4):819-847.

[3] ii L J B, Eisenhardt K M. Strategic Decision Processes in High Velocity Environments: Four Cases in the Microcomputer Industry[J]. Management Science, 1988, 34(7):816-835.

[4] Baron $\mathrm{J}$ N. The employment relation as a social relation $\hat{\xi}[\mathrm{J}]$. Journal of the Japanese \& International Economies, 1988, 2(4):492-525.

[5] Wang Y T, Suidan M T, Pfeffer J T, et al. Effect of some alkylkphenols on methanogneic degradation of phenol[J]. 1988, 54(5):1277-1279.

[6] Meyer A D, Tsui A S, Hinings C R. Configurational approaches to organizational analysis[J]. Academy of Management Journal, 1993, 36(6):1175-1195.

[7] Huang shaoan, gong mingbo. Analysis of common governance theory [J]. Economic dynamics, 2002(4):78-81.

[8] Zengjian. China development 3.0: the academic journal of various major construction (2008)[M]. Tongji university press, 2010.

[9] [9] Ostrom, Elinor (2010). Beyond Markets and States: Polycentric Governance of Complex Economic Systems (Excerpt). Transnational Corporations Review. 2(2):1-12 